\title{
Development and evaluation of different normalization strategies for gene expression studies in Candida albicans biofilms by real-time PCR
}

\author{
Heleen Nailis' ${ }^{1}$, Tom Coenye*1, Filip Van Nieuwerburgh ${ }^{2}$, Dieter Deforce ${ }^{2}$ \\ and Hans J Nelis ${ }^{1}$
}

Address: ${ }^{1}$ Laboratory for Pharmaceutical Microbiology, Ghent University, Harelbekestraat 72, B-9000, Ghent, Belgium and ${ }^{2}$ Laboratory for Pharmaceutical Biotechnology, Ghent University, Harelbekestraat 72, B-9000, Ghent, Belgium

Email: Heleen Nailis - Heleen.Nailis@UGent.be; Tom Coenye* - Tom.Coenye@UGent.be; Filip Van

Nieuwerburgh - Filip.VanNieuwerburgh@UGent.be; Dieter Deforce - Dieter.Deforce@UGent.be; Hans J Nelis - Hans.Nelis@UGent.be

* Corresponding author

Published: 04 August 2006

BMC Molecular Biology 2006, 7:25 doi:10.1186/1471-2199-7-25

This article is available from: http://www.biomedcentral.com/147/-2199/7/25

(C) 2006 Nailis et al; licensee BioMed Central Ltd.

This is an Open Access article distributed under the terms of the Creative Commons Attribution License (http://creativecommons.org/licenses/by/2.0), which permits unrestricted use, distribution, and reproduction in any medium, provided the original work is properly cited.

\begin{abstract}
Background: Candida albicans biofilms are commonly found on indwelling medical devices. However, the molecular basis of biofilm formation and development is not completely understood. Expression analysis of genes potentially involved in these processes, such as the ALS (Agglutinine Like Sequence) gene family can be performed using quantitative PCR (qPCR). In the present study, we investigated the expression stability of eight housekeeping genes potentially useful as reference genes to study gene expression in Candida albicans (C. albicans) biofilms, using the geNorm Visual Basic Application (VBA) for Microsoft Excel. To validate our normalization strategies we determined differences in ALSI and ALS3 expression levels between $C$. albicans biofilm cells and their planktonic counterparts.

Results: The eight genes tested in this study are ranked according to their expression stability (from most stable to least stable) as follows: ACTI ( $\beta$-actin)/PMAI (adenosine triphosphatase), RIP (ubiquinol cytochrome-c reductase complex component), RPP2B (cytosolic ribosomal acidic protein P2B), LSC2 (succinyl-CoA synthetase $\beta$-subunit fragment), IMH3 (inosine-5'-monophosphate dehydrogenase fragment), CPAI (carbamoyl-phosphate synthethase small subunit) and GAPDH (glyceraldehyde-3phosphate dehydrogenase).

Our data indicate that five genes are necessary for accurate and reliable normalization of gene expression data in C. albicans biofilms. Using different normalization strategies, we found a significant upregulation of the ALSI gene and downregulation of the ALS3 gene in C. albicans biofilms grown on silicone disks in a continous flow system, the CDC reactor (Centre for Disease Control), for 24 hours.

Conclusion: In conclusion, we recommend the use of the geometric mean of the relative expression values from the five housekeeping genes (ACTI, PMAI, RIP, RPP2B and LSC2) for normalization, when analysing differences in gene expression levels between $C$. albicans biofilm cells and planktonic cells. Validation of the normalization strategies described above showed that the ALSI gene is overexpressed and the ALS3 gene is underexpressed in C. albicans biofilms grown on silicone in the CDC reactor for 24 hours.
\end{abstract}




\section{Background}

Candida albicans is an important human fungal pathogen that is associated with biofilm formation on indwelling medical devices like urinary catheters, dental prostheses and silicone voice prostheses [1-3]. Cells released from these biofilms can migrate to the bloodstream and can cause systemic infections [4,5]. Fungal biofilms are highly resistant against most commonly used antimycotics [6]. Since no therapy is able to completely eradicate C. albicans biofilms, colonization of these medical devices often results in their functional loss and in most cases necessitates removal and/or replacement of the device [7]. C. albicans biofilm formation occurs in different stages of development. Initially, the cells adhere to a surface and form microcolonies. Subsequently, cells in these microcolonies form hyphae and produce an extracellular matrix, which results in a threedimensional structure [8]. The molecular basis of $C$. albicans biofilm formation and development is not completely understood. It is, however, well-established that interaction of C. albicans with host cells or inert surfaces leads to changes in gene expression. Different studies have already described changes in gene expression levels during biofilm development [9-11]. For example, Garcia-Sanchez et al. showed that approximately $5 \%$ of all C. albicans genes are differentially expressed in growing biofilms compared to stationary phase cultured planktonic cells. One of these genes, ALS1, was clearly upregulated in C. albicans biofilm cells [9]. Using various clinical isolates, O'Connor et al. recently demonstrated that when compared to planktonic cells, the ALS1 gene is overexpressed in biofilms formed on silicone elastomer using the absolute quantitative qPCR method [12]. RT (Reverse Transcriptase)-PCR studies of ALS1 in C. albicans biofilms formed on reconstituted human epithelial cells detected ALS1 gene expression over time during the destruction of the epithelium [13]. The ALS1 gene belongs to the ALS gene family, which encodes cell surface glycoproteins [14]. The ALS3 gene, another gene belonging to the ALS gene family has been shown to be upregulated in $C$. albicans hyphae, which suggests that ALS3 might also play a role in biofilm development by this organism [15].

Monitoring gene expression by measuring mRNA levels in biofilm and planktonic cells may identify candidate genes involved in biofilm formation. mRNA can be analyzed via different assays such as Northern blot and RT-PCR. However, relative quantitative PCR (qPCR) assays can detect more subtle changes in gene expression, as qPCR data can be normalised against a reference transcript to correct for differences in amount of starting material, RNA integrity, sample to sample variation and RT efficiencies [16,17]. Ideally, reference genes used in relative qPCR studies are housekeeping genes or control genes that are equally expressed in different conditions. Several housekeeping genes have already been used in C. albicans gene expression studies, including ACT1 (encoding beta-actin), PMA1 (plasma membrane ATPase pump) and TEF1 (transcript elongation factor) [18-20]. However, numerous studies have shown that the expression of many housekeeping genes is differentially regulated depending on the experimental conditions [21,22]. Recently, Vandesompele et al. showed that the use of multiple control genes results in a much more accurate and reliable normalization of gene expression data [23]. These authors developed a VBA applet called geNorm that allows the determination of the most stably expressed genes from a series of housekeeping genes and of the number of genes required for accurate normalization.

In the present study, we investigated the expression of eight housekeeping genes in C. albicans biofilm and planktonic cells by qPCR analysis and subsequent geNorm analysis. To evaluate different normalization strategies we compared ALS1 and ALS3 gene expression levels in C. albicans biofilm and planktonic cells.

\section{Results \\ RNA and cDNA quantity}

Different biological replicate samples (Bio A to Bio G and Plankt A to Plankt F for biofilm and planktonic samples, respectively) were obtained after 24 hours of growth, as described in Materials and Methods. Total RNA was extracted from biofilms and planktonic cells (grown in three independent experiments) and cDNA synthesis was performed. The RNA and cDNA concentrations of all the samples are listed in Table 1. The average RNA and cDNA concentrations of the planktonic cells were (mean \pm SD) $8.31 \pm 1.5 \mu \mathrm{g} / \mu \mathrm{l}$ and $25 \pm 2.61 \mu \mathrm{g} / \mathrm{ml}$, respectively. The average RNA and cDNA concentrations of the biofilm cells were $4.36 \pm 2.91 \mu \mathrm{g} / \mu \mathrm{l}$ and $18.83 \pm 9.45 \mu \mathrm{g} / \mathrm{ml}$, respectively.

\section{Standard curves and real time PCR efficiency}

Standard curves were generated for all the sample/gene combinations by using the Cycle Threshold $\left(\mathrm{C}_{t}\right)$ value versus the logarithm of each dilution factor. The linear correlation coefficient ranged from 0.9764 to 1.000 . Initial amplification efficiencies (E) (obtained using $300 \mathrm{nM}$ primers and $300 \mathrm{nM}$ or $200 \mathrm{nM}$ probe) ranged from $80 \%$ to $100 \%$, except for the CPA1, IMH3 and LSC2 genes $(\mathrm{E}<$ $70 \%)$. Various primer and probe concentrations were retested for those genes, until efficiencies of $>80 \%$ were obtained (data not shown). Agarose gel-electrophoresis of the amplified products showed a single band of the expected size for each qPCR assay. No primer dimers or non-specific amplification products could be observed. The inter-plate variation was $<0.5 \mathrm{C}_{\mathrm{t}}$ for every gene tested. 
Table I: RNA and cDNA concentrations of all biofilm and planktonic samples.

\begin{tabular}{cccccc}
\hline Planktonic samples & RNA $(\mu \mathbf{g} / \mu \mathrm{l})$ & cDNA $(\mu \mathbf{g} / \mathbf{m l})$ & Biofilm samples & RNA $(\mu \mathbf{g} / \mu \mathbf{l})$ & cDNA $(\mu \mathbf{g} / \mathbf{m l})$ \\
\hline Plankt A & 7.68 & 22.18 & BioA & 8.22 & 10.63 \\
Plankt B & 8.32 & 23.13 & BioB & 5.80 & 8.15 \\
Plankt C & 11.00 & 28.25 & BioC & 1.47 & 20.78 \\
Plankt D & 8.06 & 27.00 & BioD & 1.15 & 18.09 \\
Plankt E & 8.23 & 27.43 & BioE & 6.57 & 2.96 \\
Plankt F & 7.23 & 23.27 & BioF & 34.56 & 28.59 \\
& & & BioG & 4.30 & \\
\hline
\end{tabular}

\section{Expression stability of housekeeping genes}

The $M$ value of the eight housekeeping (HK) genes for all the samples (biofilm and planktonic cells) and biofilm and planktonic cells separately are listed in Table 2 . This $M$ value is defined as the average pairwise variation of one particular gene compared to all the other control genes. The gene with the lowest $M$ value is considered as the most stable gene and the gene with the highest $M$ value is excluded. A new $M$ value is calculated and this procedure is repeated until only two genes are left. These two genes have the lowest $M$ value and are therefore most stably expressed in all the samples. In Fig. 1, 2 and 3, the eight control genes are ranked according to their increasing expression stability (decreasing $M$ value), for all samples (Fig. 1), planktonic cells (Fig. 2) and biofilm cells (Fig. 3). For all samples combined, the genes are ranked from most stable to least stable as follows: ACT1 and PMA1, RIP, RPP2B, LSC2, IMH3, CPA1 and GAPDH (Fig. 1). No significant improvement in normalization could be observed by using more than five control genes (Fig. 4). When considering biofilms and planktonic cells separately, no significant improvement between the use of two or more than two housekeeping genes was obtained (Fig. 4). The two most stably expressed control genes in C. albicans biofilm and planktonic cells separately were the $A C T 1$ and RPP $2 B$ genes, and the RPP $2 B$ and PMA1 genes, respectively.

\section{ALSI and ALS3 expression in C. albicans biofilms} cDNA was amplified using a real time PCR MGB (Minor Grooving Binding) Taqman probe assay. The absolute $\mathrm{C}_{\mathrm{t}}$ values from all the qPCR assays were used to calculate the expression ratios of the ALS1 and ALS3 genes in C. albicans biofilm cells compared to their planktonic counterparts. Table 3 shows the mean expression ratios of the ALS1 and ALS3 genes in C. albicans biofilm cells calculated with the four different normalization strategies (i.e., using the five or three most stably expressed HK genes [5HK or 3HK], ACT1 as a control gene and CDNA input standardization, respectively). These ratios are based on the expression of those two genes in all the biofilm samples compared to all the planktonic samples. Statistical analysis shows a significant upregulation of the ALS1 gene in C. albicans biofilm cells $(\mathrm{p}<0.05)$. When using different normalization methods, we found that the ALS1 gene expression was three-fold (5HK genes and cDNA input), four-fold (3HK genes) or five-fold (ACT1) induced in C. albicans biofilms compared to planktonic cells. In contrast, there appeared to be a significant downregulation of the ALS3 gene in $C$. albicans biofilms $(\mathrm{p}<0.05)$. We found a fourteen-fold (5HK genes), twelve-fold (3HK genes), seven-fold (ACT1) or ten-fold (cDNA input) downregulation of the ALS3 gene.

We also compared the ALS1 and ALS3 gene expression ratios obtained with the four different normalization strategies. No statistically significant difference in ALS1 and ALS3 gene expression ratios was observed when using the geometric mean of the relative expression levels of three or five housekeeping genes nor with standardization of the cDNA input. However, normalization using ACT1 as a single reference transcript resulted in higher expression ratios, both for ALS1 and ALS3 compared to the other strategies $(\mathrm{p}<0.01)$.

Table 2: Internal control gene stability value $M$ for all housekeeping genes. A low $M$ value corresponds to a high expression stability of the particular control gene.

\begin{tabular}{|c|c|c|c|c|c|c|c|c|}
\hline \multirow[t]{2}{*}{ Samples } & \multicolumn{8}{|c|}{$M$ value for all the housekeeping genes tested } \\
\hline & GAPDH & CPAI & $\mathrm{IMH} 3$ & LSC2 & RPP2B & RIP & ACT & PMAI \\
\hline Biofilms and Planktonic cells & 0.99 & 0.91 & 0.84 & 0.79 & 0.67 & 0.61 & 0.59 & 0.59 \\
\hline Biofilms & 0.84 & 0.67 & 0.54 & 0.48 & 0.3 & 0.37 & 0.3 & 0.62 \\
\hline Planktonic cells & 0.36 & 0.27 & 0.58 & 0.49 & 0.15 & 0.19 & 0.23 & 0.15 \\
\hline
\end{tabular}




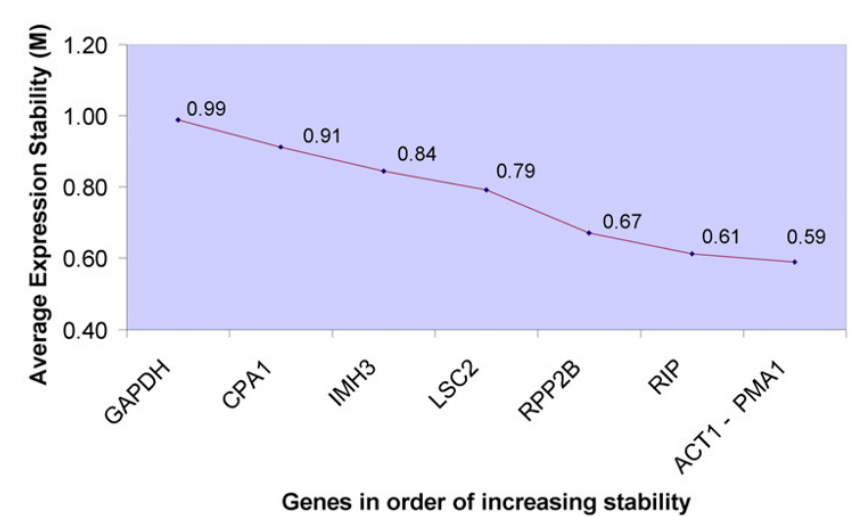

\section{Figure I}

Stability ranking of the housekeeping genes in all samples (biofilms and planktonic cells). Genes are ranked from left to right in order of increasing expression stability (decreasing $M$ value).

\section{Discussion}

This study describes a comparison between different normalization strategies used in relative RT-qPCR for the quantification of gene expression levels in C. albicans biofilm cells, grown on silicone in the $\mathrm{CDC}$ reactor, with reference to their planktonic counterparts. We also investigated ALS1 and ALS3 gene expression levels in C. albicans biofilms.

The expression levels of the ALS1 gene in C. albicans biofilm cells have previously been studied using different techniques, including absolute RT-qPCR, RT-PCR and micro-array analysis $[9,12,13]$. The choice of an appropriate reference gene for normalization in relative RT-qPCR is critical for accurate and reliable analysis of gene expression data. However, the selection of control genes used for

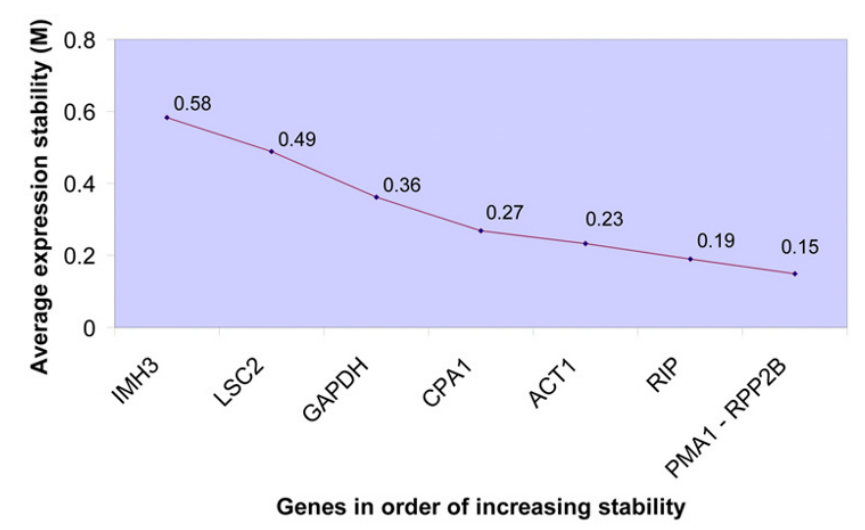

Figure 2

Stability ranking of the housekeeping genes in planktonic cells. Genes are ranked from left to right in order of increasing expression stability (decreasing $M$ value).

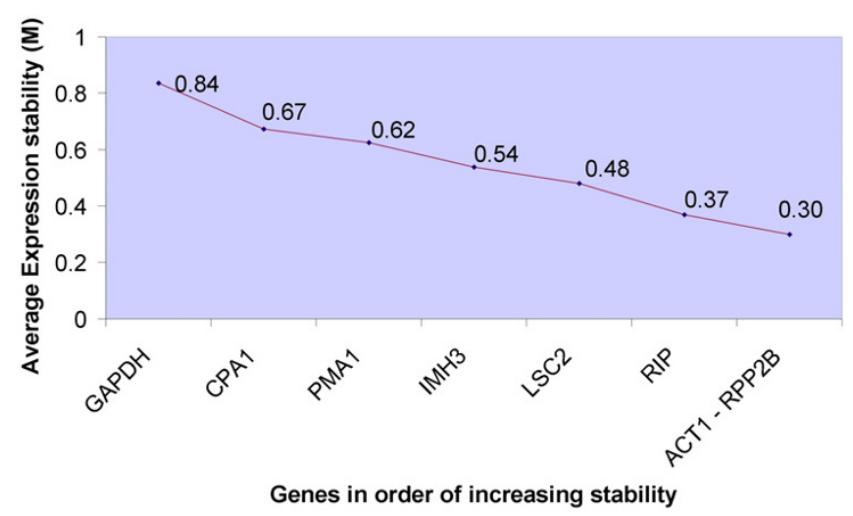

Figure 3

Stability ranking of the housekeeping genes in biofilms. Genes are ranked from left to right in order of increasing expression stability (decreasing $M$ value).

normalization of qPCR data in C. albicans is often arbitrary and/or based on observations from previous studies. Commonly used housekeeping genes are the ACT1 and PMA1 genes $[18,20]$. However, no single reference gene is expressed constantly in every experimental setup. Transcription levels of control genes used in relative RT-qPCR may vary significantly between different cell types and different developmental stages [22].

Therefore, we empirically validated the expression stability of multiple housekeeping genes in C. albicans biofilms and planktonic cells in order to use them as reference transcripts for determining gene expression data. We found that five control genes are required for accurate normalization of gene expression in C. albicans biofilms (ACT1, $P M A 1, R I P, R P P 2 B$ and $L S C 2$ ). These results suggest that the use of two, three or four control genes significantly alters the normalization factor and thus decreases the reliability and accuracy of gene expression data in C. albicans biofilms and planktonic cells. When considering biofilm and planktonic cells separately, we found that the ACT1 and $R P P 2 B$ genes (biofilms) and the PMA1 and RPP $2 B$ genes (planktonic cells) were the two most stably expressed genes. There was no significant improvement in the normalization factor when using more than two genes for normalization in biofilm cells and planktonic cells separately. Furthermore, the pairwise variation is much higher in biofilm cells than in planktonic cells, suggesting that the expression levels of the control genes tested in the present study are less stable in biofilm cells than in their planktonic counterparts.

RNA quantity is also a very important factor for accurate and reliable analysis of gene expression data. Therefore, we evaluated the amount of total RNA recovered from biofilm and planktonic cells prior to cDNA synthesis. We 


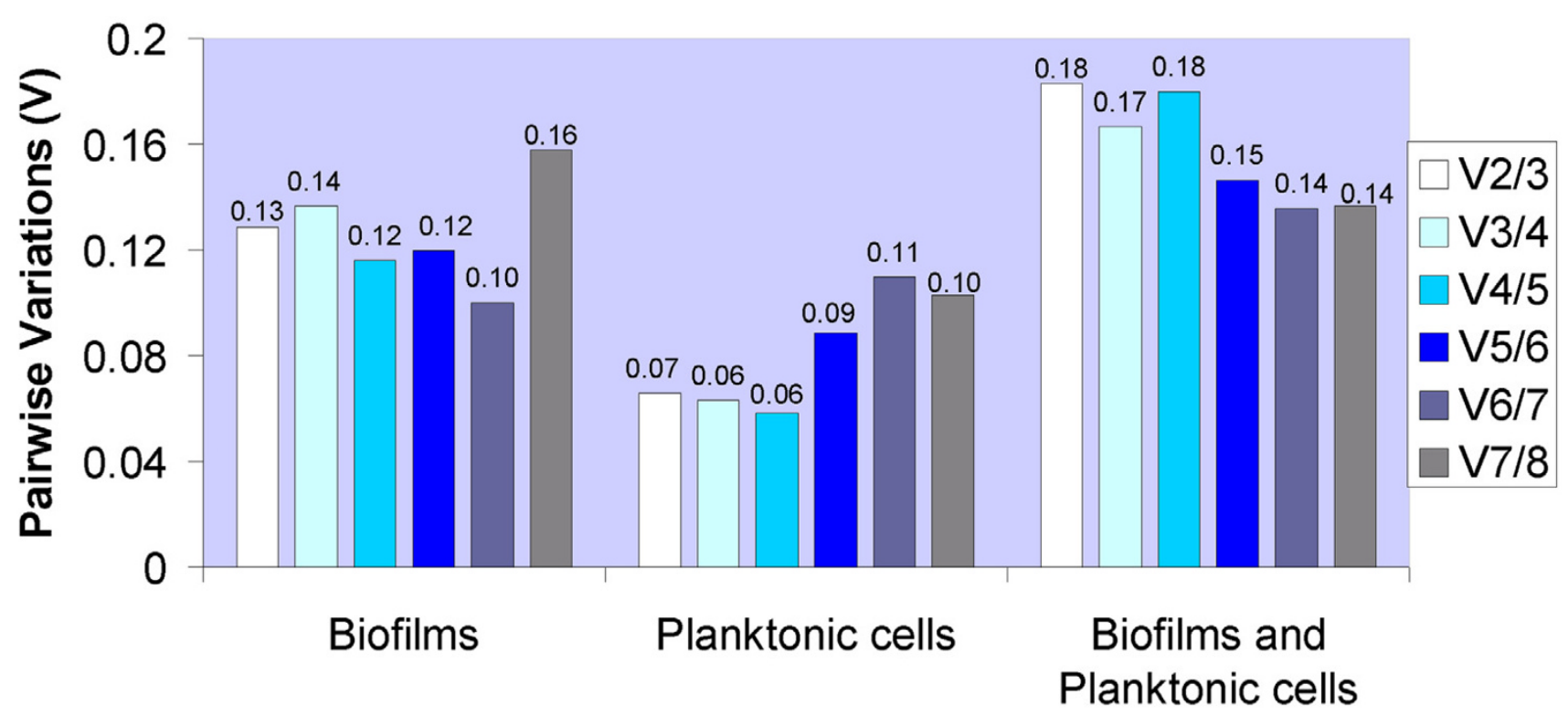

\section{Figure 4}

Pairwise variations $\left(V_{n} l_{n+1}\right)$ for all the samples (biofilms and planktonic cells) and biofilms and planktonic cells separately. Pairwise variation between every combination of sequential normalization factors were calculated to determine the minimum number of housekeeping genes required for accurate normalization in the different samples. The cut-off value, below which the inclusion of an additional housekeeping gene does not result in a significant improvement of normalization, was set at 0.15 .

found that more total RNA was extracted from planktonic cells than from biofilm cells. We also observed a larger sample-to-sample variation in amount of total RNA for biofilm cells than for planktonic cells. These results suggest that the RNA extraction from biofilm cells is less efficient. To minimize variation of the input RNA in the RT reaction, we decided to standardize the amount of input RNA. This normalization step is essential in the protocol we used (Invitrogen) since the amount of total RNA in the $\mathrm{RT}$ reaction is restricted to $5 \mu \mathrm{g}$ per reaction.

To compare different normalization strategies for gene expression analysis in C. albicans biofilms using relative
RT-qPCR, we investigated the ALS1 and ALS3 gene expression levels in $C$. albicans biofilm and planktonic cells. Compared to the other normalization strategies, normalization with ACT1 as a control gene gives significantly different results (Table 3 ). These results clearly indicate the need for a more reliable normalization method. Therefore, we suggest to use five control genes for normalization of gene expression data in C. albicans biofilms. For all normalization strategies, we observed a broad range in ALS1 and ALS3 expression ratios when comparing all "biofilm vs. planktonic" sample combinations (Table 3). Therefore, it is critical to analyze several independent samples to detect small fold changes.

Table 3: The mean expression ratios of the ALSI and ALS3 genes in all the C. albicans biofilm samples compared to all the planktonic samples calculated with four different normalization strategies.

\begin{tabular}{lcccc}
\hline Genes & \multicolumn{4}{c}{ Fold expression calculated with four different normalization strategies } \\
\hline ALSI & $\mathbf{5 H K}$ & $\mathbf{3 H K}$ & $\mathbf{A C T I}$ & cDNA \\
Mean & 2.98 & 3.67 & 5.12 & 3.35 \\
SD & 1.64 & 2.11 & 2.33 & 1.53 \\
Range & $0.67-7.54$ & $0.68-8.41$ & $1.85-10.58$ & $1.08-6.57$ \\
ALS3 & $\mathbf{5 H K}$ & $\mathbf{3 H K}$ & $\mathbf{A C T I}$ & $\mathbf{c D N A}$ \\
Mean & 0.069 & 0.083 & 0.15 & 0.10 \\
SD & 0.02 & 0.022 & 0.069 & 0.033 \\
Range & $0.042-0.13$ & $0.044-0.14$ & $0.072-0.35$ & $0.046-0.16$ \\
\hline
\end{tabular}


Table 4: Primer and MGB Taqman probe sequences and concentrations used in real time PCR.

\begin{tabular}{|c|c|c|c|}
\hline Gene symbol & Primer/probe & Gene Sequence (5'-3') & Concentration (nM) \\
\hline \multirow[t]{3}{*}{ ACTI } & Forward & TTTCATCTTCTGTATCAGAGGAACTTATTT & 300 \\
\hline & Reverse & ATGGGATGAATCATCAAACAAGAG & 300 \\
\hline & MGB probe & ATTATTTTCGTCACGGGTATT & 300 \\
\hline \multirow[t]{3}{*}{$R P P 2 B$} & Forward & TGCTTACTTATTGTTAGTTCAAGGTGGTA & 300 \\
\hline & Reverse & CAACACCAACGGATTCCAATAAA & 300 \\
\hline & MGB probe & САССTСТCCATCAGCTT & 200 \\
\hline \multirow[t]{3}{*}{$T D H I(G A P D H)$} & Forward & CGGTCCATCCCACAAGGA & 300 \\
\hline & Reverse & AGTGGAAGATGGGATAATGTTACCA & 300 \\
\hline & MGB probe & AGGTGGTAGAACTGC & 200 \\
\hline \multirow{3}{*}{ PMAI } & Forward & TTGCTTATGATAATGCTCCATACGA & 300 \\
\hline & Reverse & TACCCCACAATCTTGGCAAGT & 300 \\
\hline & MGB probe & CCAAAACCAGTTAAATGG & 200 \\
\hline \multirow[t]{3}{*}{ LSC2 } & Forward & CGTCAACATCTTTGGTGGTATTGT & 900 \\
\hline & Reverse & TTGGTGGCAGCAATTAAACCT & 900 \\
\hline & MGB probe & AGATGTGATTACGTCGCCA & 400 \\
\hline \multirow[t]{3}{*}{ CPAI } & Forward & TCTGGTGTTGCTGCCATAACTG & 300 \\
\hline & Reverse & AATTCTCCCCAATGATGAACCTT & 300 \\
\hline & MGB probe & AGACAATTGGTGAGTTATT & 200 \\
\hline \multirow[t]{3}{*}{$I M H 3$} & Forward & TATTCATATGGCATTATTGGGTGGTA & 600 \\
\hline & Reverse & AACCATTTCTGCTTGTTCTTCAGA & 600 \\
\hline & MGB probe & TGGTATCATTCATCATAACTGTAC & 400 \\
\hline \multirow[t]{3}{*}{$R I P$} & Forward & TGTCACGGTTCCCATTATGATATTT & 300 \\
\hline & Reverse & TGGAATTTCCAAGTTCAATGGA & 300 \\
\hline & MGB probe & TGGTAGAATTAGAAAGGGTCCA & 200 \\
\hline \multirow[t]{3}{*}{ ALSI } & Forward & CAACAGGCACCTCAGCATCTAC & 300 \\
\hline & Reverse & CTCCACCAGTAACAGATCCACTAGTAA & 300 \\
\hline & MGB probe & AGTGCTAATAGCGAACTT & 300 \\
\hline \multirow[t]{3}{*}{ ALS3 } & Forward & CAACTTGGGTTATTGAAACAAAAACA & 300 \\
\hline & Reverse & AGAAACAGAAACCCAAGAACAACCT & 300 \\
\hline & MGB probe & AAACTAGCTGTGAAGGTGAT & 300 \\
\hline
\end{tabular}

We have chosen to analyze the expression of ALS1 and ALS3 genes because they encode large glycoproteins implicated in adhesion $[15,24,25]$. Therefore, these genes could be involved in adhesion to silicone and may contribute to biofilm formation and development on medical devices.

C. albicans planktonic cells were harvested during stationary phase. Similarly, biofilm cells were harvested when the biofilm had reached it maximal biomass, i.e. a condition similar to stationary phase (data not shown). Our findings demonstrate that in our model system, the ALS1 gene is overexpressed in biofilms compared to their planktonic counterparts. Furthermore, we observed an underexpression of the ALS3 gene. Microscopic evaluation revealed that under the conditions used, C. albicans forms biofilms with a marked three-dimensional structure consisting of both yeast cells and hyphae. In addition, the planktonic culture contained a lot of hyphae as well. As it was previously shown that ALS3 gene expression was upregulated in hyphae [15], this could explain why we could not observe an overexpression of the ALS3 gene in 
biofilm cells. However, differences in expression between the ALS1 and ALS3 genes may indicate different functions of Als1p and Als3p in C. albicans biofilm development.

\section{Conclusion}

This is the first study which validates different normalization methods in order to study changes in fold expression of genes in C. albicans biofilms. We suggest to use the geometric mean of five housekeeping genes for the investigation of gene expression in C. albicans biofilms compared to planktonic cells. This assay could be useful in the determination of differentially expressed genes in C. albicans biofilms compared to their planktonic counterparts. Moreover, this normalization method could be applied to monitor the kinetics of ALS1 and ALS3 gene expression during biofilm development. Further information about the expression profiles in C. albicans biofilms could help to better understand the molecular basis of adhesion to and biofilm formation on silicone and other biomaterials.

\section{Methods}

\section{Strains and culture conditions}

C. albicans strain SC5314, which was kindly provided by Dr. A. Brown (Aberdeen University, UK), was used throughout this study. Cells were stored frozen at $-80^{\circ} \mathrm{C}$ using the Microbank system (Prolab Diagnostics). For every experiment a fresh culture was prepared by taking two beads from a Microbank vial and transferring them into $10 \mathrm{ml}$ Sabouraud Dextrose Broth (SDB; BD). This culture was incubated for 24 hours at $37^{\circ} \mathrm{C}$. For culturing planktonic cells and biofilms, $50 \mu \mathrm{l}$ of this suspension was added to $10 \mathrm{ml} \mathrm{SDA}$ and incubated for 16 hours at $37^{\circ} \mathrm{C}$ in a water bath with shaking.

\section{Biofilm growth}

C. albicans biofilms were grown on silicone disks (Q74735; Dow Corning) in the CDC biofilm reactor (Biosurface Technologies) [26] according to the protocol described by Honraet et al. [27], with some modifications. Cells were harvested by centrifugation, washed three times with and resuspended in $0.9 \% \mathrm{NaCl} w / v$. The resulting suspension (containing approximately $10^{8} \mathrm{CFU} / \mathrm{ml}$ ) was added to $500 \mathrm{ml}$ Yeast Nitrogen Base (YNB; BD) supplemented with $50 \mathrm{mM}$ glucose. This inoculated medium was transferred to the CDC reactor and incubated at $37^{\circ} \mathrm{C}$ on a magnetic stir plate (RET digi-visc, IKA Labortechnic) set at $80 \mathrm{rpm}$ for 24 hours, to allow cells to adhere to the silicone disks. After 24 hours, 0.2X YNB supplemented with $10 \mathrm{mM}$ glucose was pumped through the reactor for 24 hours at a flow rate of $400 \mathrm{ml} /$ hour. After 24 hours of biofilm growth, the disks were taken out of the reactor and each disk was transferred to $0.9 \% \mathrm{NaCl} w / v$. Prior to RNA extraction, disks were subjected three times to $30 \mathrm{~s}$ of sonication (Branson 3510, $42 \mathrm{kHz}, 100 \mathrm{~W}$, Branson Ultrasonics Corp.) and $30 \mathrm{~s}$ of vortex mixing. This treatment is necessary to remove the biofilm cells from the silicone [28].

\section{Planktonic growth}

After 16 hours of growth, the suspension was centrifuged and the pellets were washed three times with and resuspended in $0.9 \% \mathrm{NaCl} \mathrm{w} / \mathrm{v}$. Subsequently, $40 \mu \mathrm{l}$ of this suspension was added to $10 \mathrm{ml}$ of YNB broth supplemented with $50 \mathrm{mM}$ glucose and incubated for 24 hours at $37^{\circ} \mathrm{C}$ in a water bath with shaking. After 24 hours the cells were centrifuged and resuspended in $10 \mathrm{ml}$ diluted YNB $(0.2 \mathrm{X}$ YNB supplemented with $10 \mathrm{mM}$ glucose). These tubes were incubated for 24 hours at $37^{\circ} \mathrm{C}$ in a water bath with shaking. After 24 hours incubation, the cells were harvested by centrifugation and resuspended in $0.9 \% \mathrm{NaCl}$ $\mathrm{w} / \mathrm{v}$. Prior to RNA extraction, this $1 \mathrm{ml}$ suspension was subjected to vortex mixing and sonication, as described above.

\section{RNA extraction and quantification}

The cell suspensions were centrifuged and the supernatant was discarded. Total RNA was extracted with the Ambion Pure Yeast kit (Ambion) according to the manufacturer's instructions. Isolated RNA was DNase treated with the DNase treatment kit (Ambion) to ensure the absence of genomic DNA contamination. Further purification of total RNA was carried out with the Microcon columns according to the manufacturer's instructions (Millipore). Total RNA was quantified prior to cDNA synthesis using the RNA Quant-it kit (Invitrogen) according to the manufacturer's instructions.

\section{cDNA preparation and quantification}

First strand cDNA synthesis was performed using the Superscript II kit (Invitrogen). Five $\mu \mathrm{g}$ of total RNA and 1 $\mu \mathrm{l}$ oligodT12-18 primer $(0.5 \mu \mathrm{g} / \mu \mathrm{l})$ were added to each tube to obtain a total volume of $12.5 \mu \mathrm{l}$. Priming was carried out at $70^{\circ} \mathrm{C}$ for $20 \mathrm{~min}$. Subsequently, $2 \mu \mathrm{l} 10 \times \mathrm{RT}$ buffer (200 mM Tris-HCl pH 8.4 and $500 \mathrm{mM} \mathrm{KCl}), 2 \mu \mathrm{l}$ $25 \mathrm{mM} \mathrm{MgCl}_{2}, 1 \mu \mathrm{l} 10 \mathrm{mM}$ dNTP, $2 \mu \mathrm{l} 0.1 \mathrm{M}$ DTT, $1 \mu \mathrm{l}$ Superscript II RT (50 units/ $\mu \mathrm{l}$ ) and $0.5 \mu \mathrm{l}$ RNaseOut (Recombinant Ribonuclease Inhibitor 40 units/ $\mu$ l) were added to each reaction tube. The RT reaction was carried out at $27^{\circ} \mathrm{C}$ for $10 \mathrm{~min}$, followed by $50 \mathrm{~min}$ at $42^{\circ} \mathrm{C}$ and finally $5 \mathrm{~min}$ at $90^{\circ} \mathrm{C}$ (Amplitron Thermolyne). Subsequently, $1 \mu \mathrm{l}$ of Escherichia coli RNaseH ( 2 units/ $\mu \mathrm{l}$ ) was added to each reaction tube and the tubes were incubated for $20 \mathrm{~min}$ at $37^{\circ} \mathrm{C}$. cDNA was quantified using the OligoGreen Single Stranded Quantification kit (Invitrogen) according to the manufacturer's instructions.

\section{Development of primers and MGB Taqman probes}

Full-length gene sequences were obtained from the $C$. albicans database http://www-sequence.stanford.edu/ group/candida/search.html[29]. Primers and MGB Taq- 
man probes were designed using the Primer Express software (Applied Biosystems) according to the manufacturer's instructions. The primer and MGB Taqman probe sequences of all the genes used in this study are listed in Table 4. These sequences were compared to the C. albicans database using BLAST [30] in order to determine their specificity. Primers and MGB Taqman probes which could have resulted in non-specific signals were excluded. Eight housekeeping genes were selected based on different criteria. First, genes which are commonly used as a control for real time PCR experiments in C. albicans were included. Secondly, genes which appeared to be differentially expressed in biofilm and planktonic cells in the micro-array study of GarciaSanchez [9] were excluded. Furthermore, to avoid co-regulation of gene expression, the housekeeping genes tested were selected to belong to different functional categories. The control genes tested in this study were ACT1, PMA1, RPP2B, TDH1 (GAPDH), LSC2, CPA1, IMH3 and RIP.

\section{Real time PCR}

Real time PCR was performed in 96 well plates with the ABI 7000 apparatus (Applied Biosystems) using the MGB Taqman probe assay. The concentrations of the primer and MGB Taqman probes used in this study are listed in Table 4. Unless otherwise specified, $5 \mu \mathrm{l}$ cDNA was added to each reaction. Alternatively, the amount of cDNA was standardized and $40 \mathrm{ng}$ CDNA was added to each reaction. Each reaction contained $12.5 \mu \mathrm{l}$ Taqman Universal PCR Mastermix in a total volume of $25 \mu$. The real time PCR reactions were performed at $95^{\circ} \mathrm{C}$ for $10 \mathrm{~min}$, followed by 40 cycles of $15 \mathrm{~s}$ at $95^{\circ} \mathrm{C}$ and $1 \mathrm{~min}$ at $60^{\circ} \mathrm{C}$. For each sample a four-point standard curve was made with serial twofold dilutions $(1,1 / 2,1 / 4$ and 1/8). Primer efficiency was determined for every sample/gene combination of all the gene expression assays using the formula $E=10^{-1 / \text { slope, }}$ with "slope" being the slope of the four-point standard curve. Control samples were included on multiple plates to ensure that different plates could be compared. In addition, the samples were subjected to electrophoresis on 2.5 $\%$ agarose gels (Invitrogen) in $1 \times$ TBE buffer ( $1 \mathrm{M}$ Trizma Base, 0.9 M boric acid and $10 \mathrm{mM}$ EDTA, pH 8.4; Sigma) for 90 minutes at $100 \mathrm{~V}$. Subsequently, gels were stained with ethidium bromide to confirm the presence of the expected PCR products and the absence of unwanted nonspecific products.

\section{Data analysis using geNorm}

Gene stability analysis of different housekeeping genes was performed using the geNorm VBA applet [23]. For every control gene, the expression stability $(\mathrm{M})$ was calculated as the standard deviation of the logarithmically transformed expression ratios. This $\mathrm{M}$ value is the average pairwise variation of one particular gene compared to all the other control genes. The gene with the lowest $\mathrm{M}$ value is considered as the most stable gene and the gene with the highest $M$ value is excluded. A new $M$ value is calculated and this procedure is repeated until only two genes are left. These two genes have the lowest $\mathrm{M}$ value and are therefore most stably expressed in all the samples.

Evaluation of the number of control genes required for accurate and reliable normalization was performed by calculation of the pairwise variation (V) between ranked normalization factors (NF). NFs, based on the expression values of the most stable housekeeping genes (lowest $M$ value), were calculated using the geometric mean. For each combination of two sequential normalization factors $\left(\mathrm{NF}_{\mathrm{n}}\right.$ and $\left.\mathrm{NF}_{\mathrm{n}+1}\right)$ the pairwise variation $\left(\mathrm{V}_{\mathrm{n} / \mathrm{n}+1}\right)$ was calculated ( $\mathrm{n}$ being the number of housekeeping genes tested). A large variation between two sequential NF's means that the added gene has a significant effect on the calculated normalization factor and should therefore be included in the calculations used for normalizing the data. The cut-off value, below which the inclusion of an additional control gene was considered not to result in a significant improvement of the normalization, was set at 0.15 .

\section{Expression of ALSI and ALS3 in C. albicans biofilm cells}

ALS1 and ALS3 gene expression in C. albicans biofilms was evaluated using four different normalization strategies. Gene expression data were normalized using (i) the geometric mean of the five most stably expressed housekeeping genes (5HK genes), (ii) the geometric mean of the three most stably expressed housekeeping genes (3HK genes), (iii) ACT1 gene as a single reference transcript (ACT1), and (iv) standardization of the cDNA input (cDNA input). The normalized expression ratios of the $A L S 1$ and ALS3 genes using $5 \mathrm{HK}$ genes or $3 \mathrm{HK}$ genes were calculated according to the procedure described by Vandesompele et al. [23]. Over- or underexpression of these two genes relative to the ACT1 gene was calculated as described by Pfaffl [31]. ALS1 and ALS3 gene expression data obtained by normalization of the input CDNA were calculated using the delta delta $\mathrm{C}_{\mathrm{t}}$ method [32].

\section{Statistical analysis}

Statistical analysis was performed using the SPSS 11.0 software (SPSS). One-way ANOVA was used to compare the four different normalization strategies.

A one-sample two-tailed t-test was used to determine whether differences in ALS1 and ALS3 gene expression between $C$. albicans biofilms and planktonic cells were statistically significant.

\section{Authors' contributions}

HN participated in the design of the study, performed all the experimental procedures, carried out the data analysis 
and is the primary author of this manuscript. TC conceived the study, carried out the data analysis and helped to draft the manuscript. DD and FVN participated in the study design. HJN participated in the design and coordination of the study. All authors read and approved the final manuscript.

\section{Acknowledgements}

This work was funded by the Belgian Federation against Cancer and the Bijzonder Onderzoeks Fonds (BOF) (Ghent University).

\section{References}

I. Hawser SP, Douglas LJ: Biofilm formation by Candida species on the surface of catheter materials in vitro. Infect Immun I994, 62:915-921.

2. Busscher HJ, Geertsema-Doornbusch Gl, van der Mei HC: Adhesion to silicone rubber of yeasts and bacteria isolated from voice prostheses: influence of salivary conditioning films. J Biomed Mater Res 1997, 34:201-2I0.

3. Bauters TG, Moerman M, Vermeersch H, Nelis HJ: Colonization of voice prostheses by albicans and non-albicans Candida species. Laryngoscope 2002, I I 2:708-7 I2.

4. Douglas LJ): Candida biofilms and their role in infection. Trends Microbiol 2003, I I:30-36.

5. Kojic EM, Darouiche RO: Candida infections of medical devices. Clin Microbiol Rev 2004, 17:255-267.

6. Ramage G, Bachmann S, Patterson TF, Wickes BL, López-Ribot JL Investigation of multidrug efflux pumps in relation to fluconazole resistance in Candida albicans biofilms. J Antimicrob Chemother 2002, 49:973-980.

7. Eerenstein SEJ, Grolman W, Schouwenburg PF: Microbial colonization of silicone voice prostheses used in laryngectomized patients. Clin Otolaryngol 1999, 24:398-403.

8. Chandra J, Kuhn DM, Mukherjee PK, Hoyer LL, McCormick T, Ghannoum MA: Biofilm formation by the fungal pathogen Candida albicans: development, architecture and drug resistance. Bacteriol 200I, I 83:5385-5394.

9. García-Sánchez S, Aubert S, Iraqui I, Janbon G, Ghigo JM, d'Enfert C Candida albicans biofilms: a developmental state associated with specific and stable gene expression patterns. Eukaryot Cell 2004, 3:536-545.

10. Marchais V, Kempf M, Licznar P, Lefrançois C, Bouchara JP, Robert R, Cottin J: DNA array analysis of Candida albicans gene expression in response to adherence to polystyrene. FEMS Microbiol Lett 2005, 245:25-32.

II. Murillo LA, Newport G, Lan CY, Habelitz S, Dungan J, Agabian NM: Genome-wide transcription profiling of the early phase of biofilm formation by Candida albicans. Eukaryot Cell 2005, 4:1562-1573.

12. O'Connor L, Lahiff S, Casey F, Glennon M, Cormican M, Maher M: Quantification of ALSI gene expression in Candida albicans biofilms by RT-PCR using hybridisation probes on the LightCycler. Mol Cell Probes 2005, I9:153-162.

13. Green CB, Cheng G, Chandra J, Mukherjee P, Ghannoum MA, Hoyer LL: RT-PCR detection of Candida albicans ALS gene expression in the reconstituted human epithelium (RHE) model of oral candidiasis and in model biofilms. Microbiology 2004, I 50:267-275.

14. Hoyer LL: The ALS gene family of Candida albicans. Trends Microbiol 200I, 9:176-180.

15. Hoyer LL, Payne TL, Bell M, Myers AM, Scherer S: Candida albicans ALS3 and insights into the nature of the ALS gene family. Curr Genet 1998, 33:45 I-459.

16. Freeman WM, Walker J, Vrana KE: Quantitative RT-PCR: pitfalls and potential. Biotechniques 1999, 26: I I2-125.

17. Bustin SA: Quantification of mRNA using real time reverse transcription PCR (RT-PCR): trends and problems. J Mol Endocrinol 2002, 29:23-39.

18. Frade JP, Warnock DW, Arthington-Skaggs BA: Rapid quantification of drug resistance gene expression in Candida albicans by reverse transcriptase lightcycler PCR and fluorescent probe hybridization. J Clin Microbiol 2004, 42:2085-2093.
19. Zhao X, Oh SH, Yeater KM, Hoyer LL: Analysis of the Candida albicans Als2p and Als4p adhesins suggests the potential for compensatory function within the ALS family. Microbiology 2005, I5I:1619-1630.

20. Chau AS, Mendrick CA, Sabatelli FJ, Loebenberg D, McNicholas PM: Application of real-time quantitative PCR to molecular analysis of Candida albicans strains exhibiting reduced susceptibility to azoles. Antimicrob Agents Chemother 2004, 48:2 I 24-2I3I.

21. Bustin SA: Absolute quantification of mRNA using real-time reverse transcription polymerase chain reaction assays. J Mol Endocrinol 2000, 25:169-193.

22. Thellin O, Zorzi W, Lakaye B, De Borman B, Coumans B, Hennen G, Grisar $T$, Igout $A$, Heinen $E$ : Housekeeping genes as internal standards: use and limits. J Biotechnol 1999, 75:29|-295.

23. Vandesompele J, De Preter K, Pattyn F, Poppe B, Van Roy N, De Paepe A, Speleman F: Accurate normalization of real-time quantitative RT-PCR data by geometric averaging of multiple internal control genes. Genome Biol 2002, 3:RESEARCH0034.

24. Fu Y, Rieg G, Fonzi WA, Belanger PH, Edwards JE, Filler SG: Expression of the Candida albicans gene ALSI in Saccharomyces cerevisiae induces adherence to endothelial and epithelial cells. Infect Immun 1998, 66: I 783-I 786.

25. Fu Y, Ibrahim AS, Sheppard DC, Chen YC, French SW, Cutler JE, Filler SG, Edwards JE: Candida albicans Als I p: an adhesin that is a downstream effector of the EFGI filamentation pathway. Mol Microbiol 2002, 44:6I-72.

26. Donlan RM, Piede JA, Heyes CD, Sanii L, Murga R, Edmonds P, ElSayed I, El-Sayed MA: Model system for growing and quantifying Streptococcus pneumoniae biofilms in situ and in real time. Appl Environ Microbiol 2004, 70:4980-4988.

27. Honraet K, Goetghebeur E, Nelis HJ: Comparison of three assays for the quantification of Candida biomass in suspension and CDC reactor grown biofilms. J Microbiol Methods 2005, 63:287-295.

28. Heersink J: Basic biofilm analytical methods. In The biofilm Laboratory: Step-by-Step Protocols for Experimental Design, Analysis, and Data Interpretation Edited by: Hamilton M, Heersink J, Buckingham-Meyer K, Goeres D. Bozeman: Cytergy Publishing; 2003:16-23.

29. Jones T, Federspiel NA, Chibana H, Dungan J, Kalman S, Magee BB, Newport G, Thorstenson YR, Agabian N, Magee PT, Davis RW, Scherer S: The diploid genome sequence of Candida albicans. Proc Natl Acad Sci USA 2004, I 1 I:7329-7334.

30. Altschul SF, Madden TL, Schäffer AA, Zhang J, Zhang Z, Miller W, Lipman DJ: Gapped BLAST and PSI-BLAST: a new generation of protein database search programs. Nucleic Acids Res 1997 , 25:3389-3402.

31. Pfaff MW: A new mathematical model for relative quantification in real-time RT-PCR. Nucleic Acids Res 200I, 29:2002-2007.

32. Livak KJ, Schmittgen TD: Analysis of relative gene expression data using real-time quantitative PCR and the 2 -delta delta $\mathrm{Ct}$ method. Methods 200I, 25:402-408.
Publish with BioMed Central and every scientist can read your work free of charge

"BioMed Central will be the most significant development for disseminating the results of biomedical research in our lifetime. "

Sir Paul Nurse, Cancer Research UK

Your research papers will be:

- available free of charge to the entire biomedical community

- peer reviewed and published immediately upon acceptance

- cited in PubMed and archived on PubMed Central

- yours - you keep the copyright
BioMedcentral 